\title{
IMPRESSIVE SMART CARD BASED ELECTRONIC VOTING SYSTEM
}

\author{
G.Keerthana ${ }^{1}$, P.Priyanka ${ }^{2}$, K.Alise Jenifer ${ }^{3}$, R.Rajadharashini ${ }^{4}$, Aruna Devi.P ${ }^{5}$ \\ ${ }^{l}$ ECE, Sasurie College of Engineering, Tamil Nadu \\ ${ }^{2}$ ECE, Sasurie College of Engineering, Tamil Nadu \\ ${ }^{3}$ ECE, Sasurie College of Engineering, Tamil Nadu \\ ${ }^{4}$ ECE, Sasurie College of Engineering, Tamil Nadu \\ ${ }^{5}$ Assistent Professor/ECE, Sasurie College of Engineering, Tamil Nadu
}

\begin{abstract}
The impressive smart card based electronic voting system is introduced to ensure apposite voting procedures and voting counts. This idea prevents the illegal acts against the voting system and provides the voter authentication in an effective manner. This proposal plans to provide a fortification for each and every votes. It entirely changes the status of the election process and ensures the integrity of electoral system. The primary idea of this paper is to make the voters as to have a trust in election through the methods of taking fingerprint and providing a smart card to each user to promise their uniqueness in the voting system and reduces the work of election committee. At the same time the result of the election process will be automatically declared to the public. With the help of this method, the person can vote from any election booth easily.
\end{abstract}

Keywords- Electronic voting system, authentication, biometric fingerprinting method, smart card

\section{INTRODUCTION}

E-voting has been a very controversial topic ever since the presidential elections in the U.S. in 2000.Many security flaws were found. The standards for the implementation of e-voting systems were shown to be too weak and many (scientific) experts expressed their negative opinions on evoting.

Nevertheless, efforts are still made to introduce e-voting in countries that use traditional paper ballots. E-voting is an election method in which the votes are cast or collected electronically. A computer system whose main element is an software component that maps the voting procedure electronically is called an e-voting system.

A direct recording electronic (DRE) machine is a special case of such a system as it implements all steps in the voting process, from start to declaration of results. There are two different forms of voting: distance and presence voting. In present, the person can cast in the election booth under the direction of the election's organization.

The present voting are conventional elections in polling stations or voting with e-voting machines. In distance voting, the voter acts without the supervision of the electoral commission and they can poll their votes from a place other than a polling booth, such as casting absentee ballots via mail or internet voting.

The finger print sensor gets the finger print of the voters and it passes it to the computer. In computer the finger print image is compared with the image in database. If it matches, the computer informs the command the person is valid to the micro controller and displayed. If anyone try to poll their vote beyond the time limit, system will be blocked.
It reduces the time in both casting a vote and declaring the results compared to the old paper ballot system. However, they have been under the suspicion over their alleged tamping arability and security problems during elections (especially after the 2009). After reign of Delhi High Court ,and other courts and demands from various political issues ,the Election Commission determined to introduce electronic voting with Voter-verified paper audit trail (VVPAT) system. The Voter-verified paper audit trail system is introduced in 8 of 543 parliamentary constituencies as a pilot project.

\section{OVERVIEW OF ELECTRONIC VOTING} SYSTEM

\subsection{Electronic Voting Machine}

Electronic voting machine is a device that has the programmed to conduct a campaign of election in a fair and quick a manner. The idea of electronic voting machines (EVM) started by the chief election commissioner in 1977. This was a technical development of the Electronics Corporation of India Limited (ECIR), Hyderabad and with Bharat Electronics Limited (BEL), Bangalore. The full control of the machine is with the presiding officer or the chief polling officer of the area as the control unit while the other unit called balloting unit is placed inside the compartment. Electronic Voting Machine (EVM) retains all the characteristics of voting by papers, while making polling a lot more convenient and absolutely consistent. And, also it, helps maintain total voting privacy without the use of ballot papers.

An Electronic Voting Machine consists of two Units - a Control Unit and a Balloting Unit - joined by a five-meter cable. The balloting unit enables the voters to provide their votes. Each balloting unit can accommodate more than 10 
candidates. Such units can be connected to a single control unit. EVMs are powered by an ordinary 6 volt alkaline battery. This design helps the use of EVMs throughout the country without interruptions because several parts of India do not have power supply and/or erratic power supply.

Due to the low voltage, there is absolutely no risk of any voter getting a shock. presently, it can record a maximum of nearly 4000 votes, which is equally for a election booth as they typically have no more than 1400 voters assigned. At present, an EVM can furnish to a maximum of candidates. There is specialty for sixteen candidates in a polling Unit. If the total number exceeds, a second Unit can be linked equivalent to the first Balloting Unit and so on till a maximum of 4 units. The conventional method of polling is used if the number of candidates exceeds 64 .

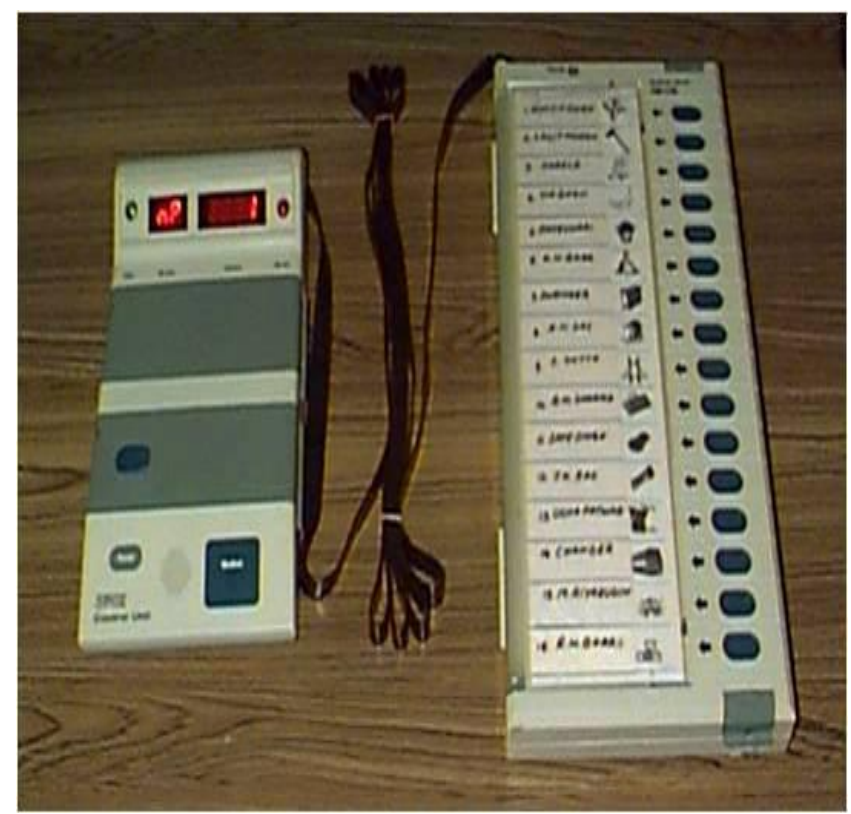

Fig 1: Electronic Voting Machine

In this paper it is not possible to vote more than once by pressing the button repeatedly. Suddenly a particular button on the Balloting Unit is pressed, the vote is recorded for that correct candidate and the machine gets sheltered. Even if the button is pressed again or any other button, no vote will be polled. This manner the machine gives the principle of "one person, one vote". Simple to operate and can be made in a short time, Preserves voting concealment. No scope for false votes. Helps in fast and perfect vote counts - possible to declare results on spot. Recycled by simply erasing votes recorded in.

\subsection{Voter Identification Card}

In August, 1993, the Election Commission of India ordered the making of photo identity cards for all voters of the country in an attempt to improve the accuracy of the electoral rolls and prevent electoral fraud. To take advantage of the latest technical inventions, the Commission provided guidelines for the Electors Photo Identity Card (EPIC) Program. More than million identity cards have been supplied across India till now.
The voter ID card or EPIC is an identification card issued by the Election Commission to all eligible voters (Indian citizens who are above 18 years of age) to enable voter identification on the Day of election. Those who are in the voter's list are eligible to receive an Identification card. These carry personal details and a distinct serial identification number.

The EPIC proves to be a unique identity document for all Indians. It also acts as an identity proof for getting other provisions also. In fact today, almost all government organizations, they ask for a voter id number. A voter ID card is also essential for listing in the electoral roll in case a person migrates to a place other than the place of his/her domicile.

To get a voter ID card or EPIC, first of all you have to get registered as a voter by filling and submitting the form 6/8/8A to the electoral Register officer (ERO) and then submit the form 001A to apply for a voter individuality Card. If the persons are previously registered i.e. your details are already in the collective database, you can suggest the Form to the ERO.

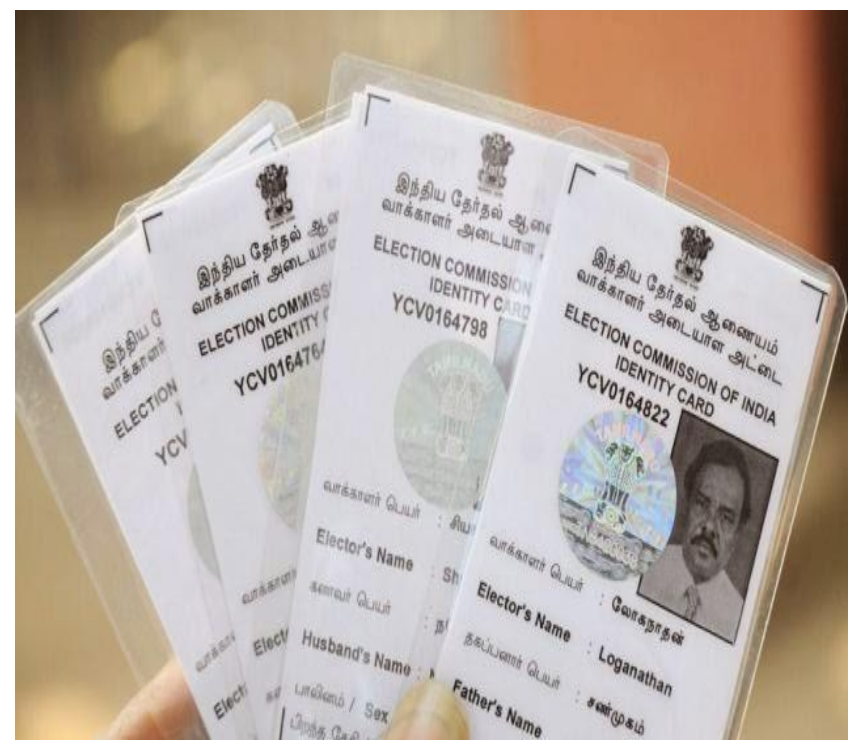

Fig 2: Voter Identification Cards

The technique in this paper replaces the voter id card with the RFID card such that the manual checking of the voter id card is reduced hence the time gets reduced.

\section{TECHNIQUES OF PROPOSING SYSTEM}

Electronic voting (also known as e-voting) is a term encompassing several different types of voting, embracing both electronic means of casting a vote and electronic means of counting votes.

It can also involve transmission of ballots and votes by way of telephones, secretive computer networks. The idea of providing smart card like swipe card to each people in the constitution area and implementing the system access on the basis of biometric finger printing method 


\subsection{Procedure in the Proposed Voting System 16F877A}

The procedure in the working of Impressive smart card based election voting system is understood from the block diagram as below.

The block diagram consisting of following blocks,

$\begin{array}{ll}> & \text { EEPROM } \\ > & \text { FINGER PRINT MODULE } \\ > & \text { KEYBOARD } \\ > & \text { LCDZER DISPLAY } \\ > & \text { RFID MODULE WITH RFID CARD } \\ > & \text { PIC MICROCONTROLLER (16F877A) }\end{array}$

This paper has the above module which is the combined method of RFID and the Fingerprint interface which is the main idea in providing security to the system. Using this combined process the malpractice with irrelevant materials is avoided.

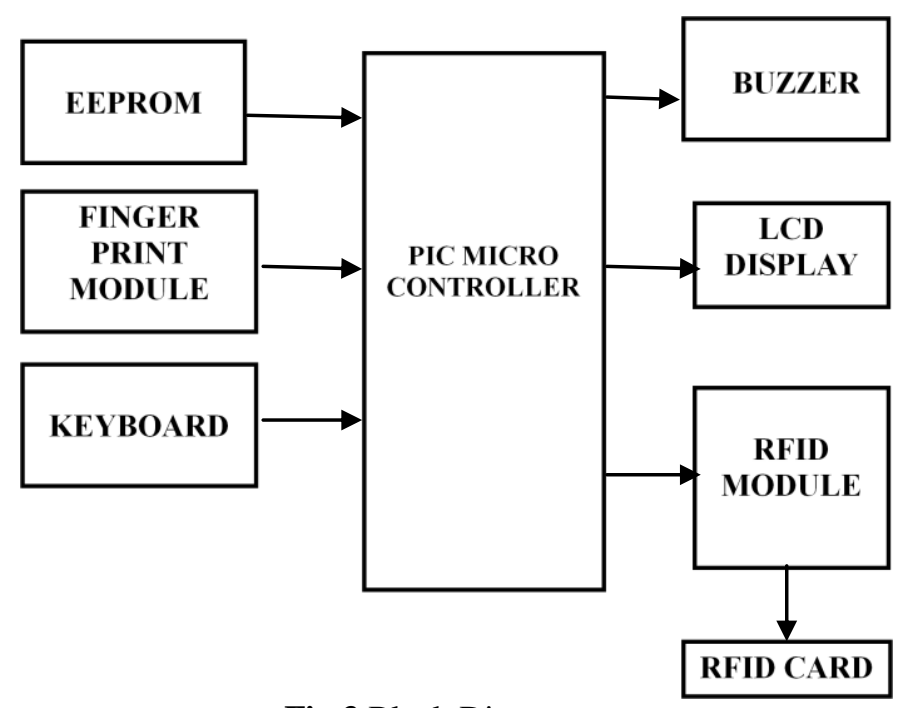

Fig 3 Block Diagram

The procedure in this paper is to implement the voting procedure is followed by checking the voter ID card prior to the main electoral process and then only the person is allowed to move inside the polling booth. This verification is done by the officers inside the polling area and hence this ids manual. There the smart card which the person has is swiped and then his fingerprint is placed in the module kept nearby.

Finally if both the smart id number and the fingerprint impressed matches with the database the person can cast their vote for the candidate they specify. The lists of the parties in that constitution who are competing are displayed in the screen. From that the person can choose the candidate and then can vote.

The interface of the pic microcontroller and the RFID module is done by the MICRO $\mathrm{C}$ tool which controlls the reading and operation of the RFID portion. The databases of the voting candidates are done and stored in the VB.NET programming with the MS ACCESS specializations.the registration of the candidates, the start and end of voting process is done by the official person and it is done in the server system. This is protected by the password which is confidential. Only the voting client system is placed inside the voting compartment and controlled by the server.

The highest RFID range can be achieved by,

$>$ The power available within the RFID tag is to respond

$>$ The power available within the reader to communicate

$>$ The environmental conditions and structures are significant to SNR (signal to noise ratio)

In an RFID system the transponder that contains the data to be transmitted is known as RF tag. These are either active or passive.

The pin functions of RFID are denoted in the table below,

Table 1 RFID Pin specification

\begin{tabular}{|l|l|l|}
\hline 1 & VCC & $5 \mathrm{~V}$ \\
\hline 2 & GN & GND \\
\hline 3 & BEE & BEEP AND LED \\
\hline 4 & ANT & NO USE \\
\hline 5 & ANT & NO USE \\
\hline 6 & SEL & $\begin{array}{l}\text { HIGH IS RS232,LOW IS } \\
\text { WEIGNAND }\end{array}$ \\
\hline 7 & RS232 & RS232 \\
\hline 8 & D1 & WEIGNAND DATA1 \\
\hline 9 & D0 & WEIGNAND DATA0 \\
\hline
\end{tabular}

It is a short range communication technology. This term (RFID) is used to indicate various technologies which use radio frequency waves used to customarily sort out people or objects. This technology is similar to the bar code identification systems but the only difference is that RFID does not rely on the line-of-sight reading. 
The electromagnetic or the electrostatic coupling in the RF portion of the electromagnetic spectrum is used to transmit signals. This system consist of an antenna and a transceiver, which read the RF and transfer the information to the device(reader) and a transponder or RF tag, which contains the RF circuitry and information to be transmitted.

It transmits information to the reader that converts the radio waves reflected back from the RFID tag into digital information and it can be passed onto the computer to examine the data. It also consists of databases, readers and networks. It is also used in some hospitals to track patient's location, and to provide real time tracking of the location of doctors and nurses in the hospital. It is a frontrunner technology in future for automatic identification.

\subsection{Fingerprint Module}

A Fingerprint is an impression of the friction ridges of all or any part of finger. The method of fingerprinting is a type of biometric recognition mainly used for identifying the applications of internet. This method is leading one of low cost and unique, can't be changed easily and the stealing and losses are not possible.

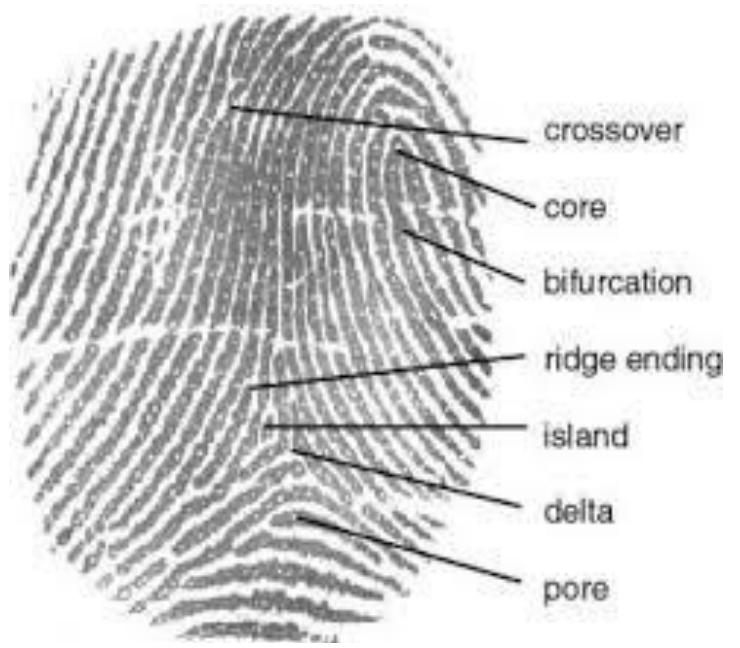

Fig 5 Fingerprint

Fingerprinting is a mean of hardware intellectual property protection (IP) focus on low design effort and less attention on the integration of IP. The authorship is detected through different data of fingerprints without continuous separation of IP owner's signature in the instant of fingerprinting. The fingerprinting challenges considerate IP voter marking and creditability of low design overheads and transparency of flow specifications.

This paper gives the pattern of fingerprint matching and its accuracy in identification procedures compared to other authentication processes. The uniqueness is main thing that even the identical twin doesn't have the same pattern of fingerprint. The fingerprinting is now a day's taken for all fingers in a hand for the sake of occupational workers who have a lot of works which are manual, prone to get injuries in hands (e.g. cuts and bruises).
Modern fingerprint methodology, aided by central processing unit and laser machinery, these methods can speed the process of matching, and it gives an mammoth comparative specimens with database. The method of digital fingerprint reading and its techniques are explained above

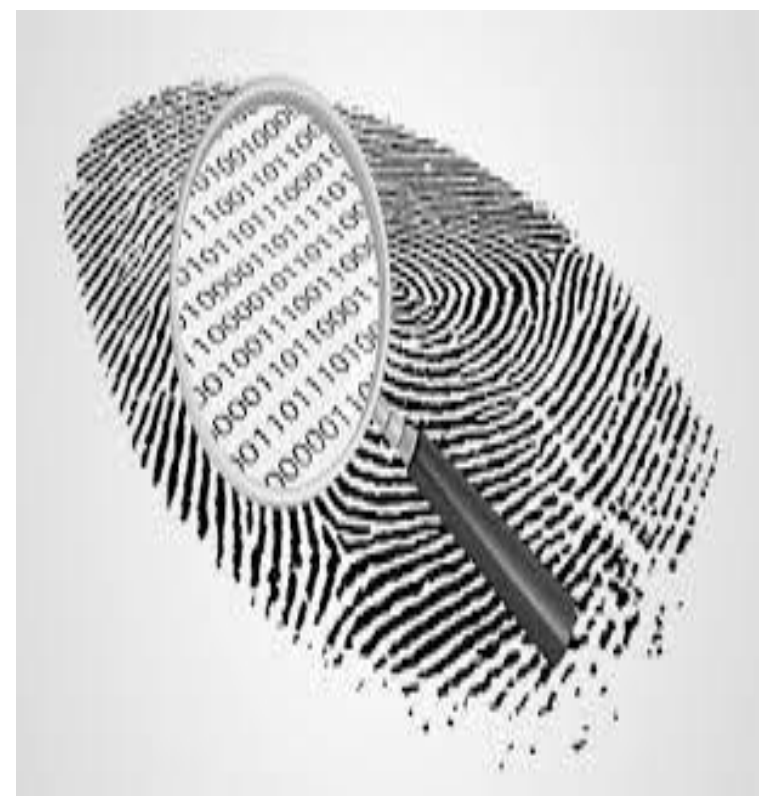

Fig 6 Digital reading of fingerprint

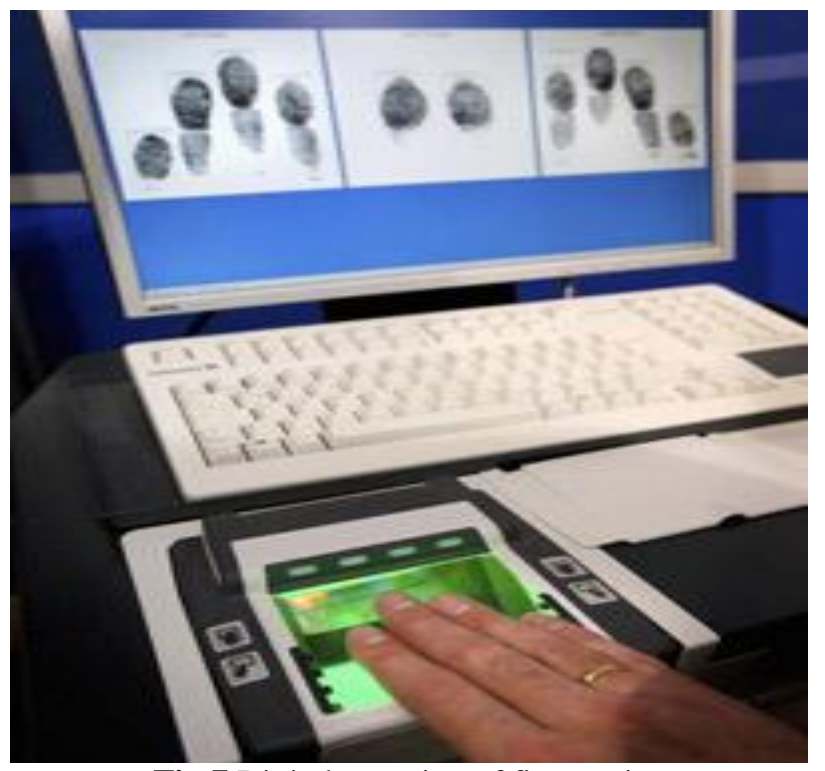

Fig 7 Digital scanning of fingerprint

\section{PERFORMANCE ANALYSIS}

The performance of the system is based on the database which we are going to implement in the version of VISUAL BASIC (VB.NET) and the related accessing methods using PIC microcontroller and other modules in the system. The security of the information and the voting procedures are made secure such that there will be rigging free election process. 


\section{CONCULSION}

This paper focuses on the voting technologies that provides assurance to the people who really have right to vote in their constitution and ensures secured riggless voting using the methods of fingerprinting and the uniqueness in the voting procedures are promised by on spot declaration of results of that election.

\section{REFERENCES}

[1]. Schurmann, C.; IT Univ. of Copenhagen, Copenhagen, Denmark . -Electronic Elections: Trust Through Engineering\|, First international workshop Requirements Engineering for e-Voting Systems (RE-VOTE), 2009.

[2]. Lin Hong. "Automatic Personal Identification Using Fingerprints", Ph.D. Thesis, 1998.

[3]. D. Maltoni, D. Maio, A. K. Jain, and S. Prabhakar, Handbook of Fingerprint Recognition. New York: Springer-Verlag, 2003.

[4]. Anil K. Jain and David maltoni., Handbook of Fingerprint Recognition, Springer-verlag New York, Inc., Secaucus, NJ, USA, 2003.

[5]. Tadayoshikohno_ Adamstubblefield Avield Rubidans.Wallach - Analysis of an Electronic Voting systemll, IEEE symposium on Security and Privacy 2004. [6]. Y. A. Zuev and S. Ivanon, -The voting as a way to increase the decision reliability, $\|$ in Proc. Foundations of Information/Decision Fusion with Applications to Engineering Problems, Washington, DC, Aug. 1996, pp.206-210.

[7]. Davide Maltoni, Anil K.Jain, Dario Maio, S.Prabhak, Handbook of fingerprint Recognition $2^{\text {nd }}$ Ed, London , British : SpringerVerlag, 2009.

[8]. Dhruv Batra, Girish Sanghal, "Gabor Filter based Fingerprint Classification using Support Vector Machines" in proc. IEEE India annual conference, 2004, p. 256. 